\title{
SôBRE UM TOPÁZIO DE ARASSUAí (MINAS GERAIS)
}

\author{
J. Moacyr V. Coutinho \\ (3 rlesenhos no texto)
}

A origem do topázio ainda não é bem conhecida em seus pormenores. E' certo porém, que resulta de ações pneumatolíticas nas zonas de contacto dos granitos. Durante a cristalização do magma, vapores de ácido fluorídrico ou fluoretos, talvês fluoreto de silício, teriam agido sòbre os silicatos naturais de alumínio, originando-se então, o fluosilicato de alumínio $|\mathrm{Al}(\mathrm{F}, \mathrm{OH})|_{2 .} \mathrm{SiO}_{4}$, ou topázio, Do'elter (2).

Entre os autores que já publicaram estudos sỏbre os topázios do Estado de Minas Gerais, cilaremos Kenngott (5), que estuda de preferência o topázio do centro de Minas Gerais, e H. Laspeyres (6) qu'e também analiza o topázio dêsse Estado, mas aqui, sob o aspecto do hemimorfismo.

O topázio ocorre no Brasil, em importantes depósitos na Bahia (Conquista); norte de Minas Gerais (Arassuaí, Theophilo Ottoni, Salinas) e centro do mesmo estado, nas localidades de Ouro Preto e Dom Bosco. Cada região possue cristais característicos: os da Bahia são policróicos, os do norte de Minas, azulados, esverdeados ou incolòres, biterminados e em geral avantajados em tamanho. Ainda nesta última região, são comuns os topázios rolados. Os do centro de Minas são róseos ou amarelos, de tonalidades diversas e não se apresentam em grandes cristais. Aí, o topázio se acha associado à litomarga e quartzo bem cristalizado, imerso em xisto micáceo decomposto, de origem ainda discutida, como se poderá deduzir dos estudos de Orville A. Derby, Djalma Guimarães e H. C. Alves de Souza (4), H. Gorceix e d'Eschwege, êstes dois últimos citados respectivamente por Francisco I. Ferreira (3) e Orville A. Derby (1).

Em Arassuai, segundo Leonardos (7), o topázio se encontra nos diques de pegmatito que corlam o gneiss.

Do município de Arassuaí, já foram retirados grandes cristais, com pêsos superiores a $100 \mathrm{~kg}$. e que hoje enriquecem coleções norte-americanas. Éstes cristais foram estudados por Esmeraldino Reis (8) com a determinação das formas encontradas em 7 de 10 cristais exportados. Outro topázio dessa mesma região, pertencente ao Departamento de Mineralogia e raro pelas 
suas formas, grandeza e característicos morfológicos, foi objeto de estudo de J. Patrima da Silva (9).

O cristal que nos propomos estudar e que hoje pertence à coleção mineralógica do Departamento de Mineralogia e Petrografia da Faculdade de Filusofia, Ciências e Letras da Universidade de São Paulo, foi doado por gentileza do sr. Odilon Loureíro da Cunha Provém da região de Arassuaí e possue hábito semellante aos dos cristais acima referidos. E' perfeitamente transparente e de colorido levemente azul. Pesa $12,440 \mathrm{~kg}$ e apresenta na direção de seus eixos cristalográficos, as seguintes dimensões:

$\mathrm{XX}=17,85 \mathrm{~cm}, \quad \mathrm{YY}^{\prime}=23,5 \mathrm{~cm} \quad$ e $\quad Z Z^{\prime}=18,1 \mathrm{~cm} \quad($ fig. 1$)$

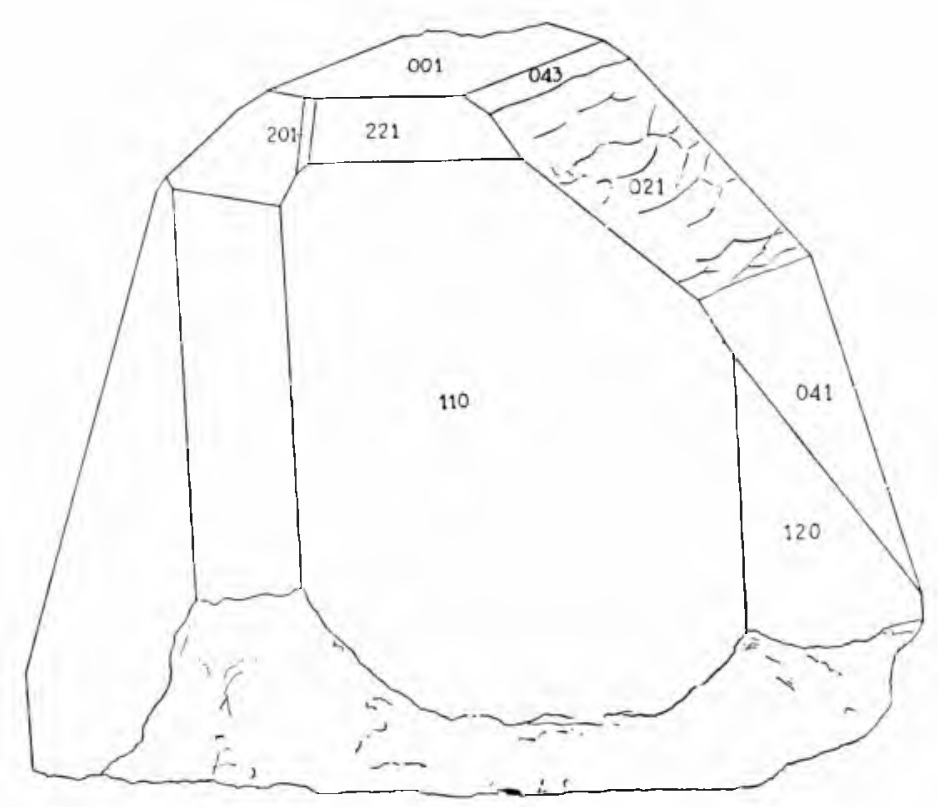

FIG. 1

As faces, de prismas verticais $(120),(110)$. (110) e (120), são perfeitamente limpidas e estriadas verticalmente. As faces do lado oposto são embaçadas. As faces de prismas horizontais são tambêm límpidas, salvo a de símboío (201), que como as faces de pinacoide hasal e da única bipirâmide $\{221\}$, é translúcida. Algumas faces apresentam característicos interessantes; assim, (041) é estriada horizontalmente; $(021)$ e $(0 \overline{2} 1)$ exibem leves irregularidades de crescimento. Tais irregularidades se concretizam em pequenas elevações qu'e se superpoiem. As faces (043) e (043) também são ligeiramente irregulares. O pinacoide (001) apresenta imperfeições de crescimento sob a forma de pequen:nos losangos com o eixo maior orientado segundo yy' Algumas dessas saliências são comparáveis a lentes biconvexas, dada a curvilinidade das margens correspondentes aos vértices obtusos. 
Tais figuras correspondem perfeitamente às que se observam nas faces de diamante, estudado por A. F. Williams (10) e denominadas por este autor, de "growth structure" A única face do prisma horizontal (201) apresenta também, pequenas reintrâncias triangulares com vértice nítido, para a parte superior.

A clivagem paralela ao pinacoide basal é bem visível por seus traços no interior do cristal. A fratura conchoidal também is nitida nas regiões em que o cristal se acha quebrado. Inclusões pardacentas sem orientação alguma podem ser registadas no interior do topázio.

O cristal não apresenta grande número de formas, como mostra a figura 2 . São as seguintes:

$$
\{120\},\{110\},\{043\},\{021\},\{011\},\{201\},\{221\} \text { e }\{001\}
$$

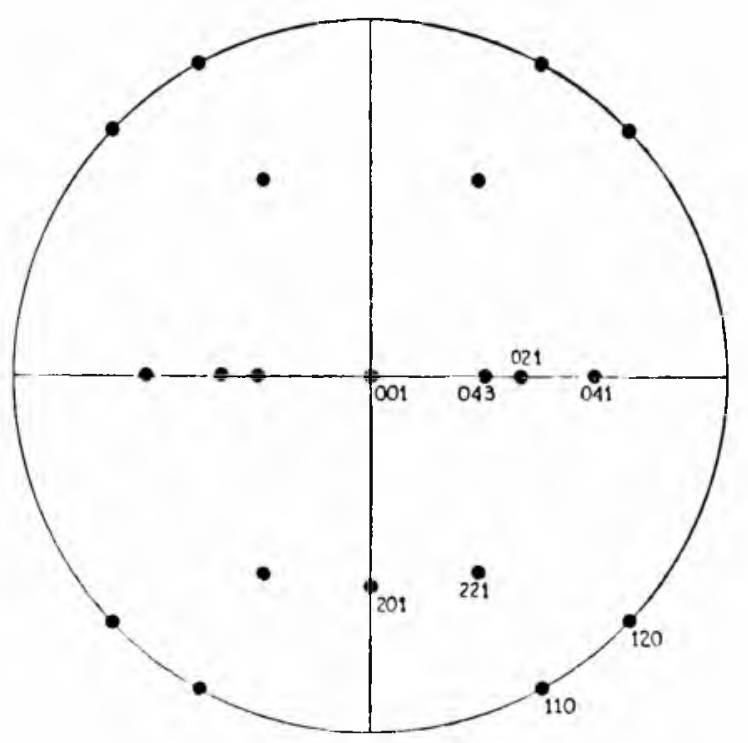

FIG. 2

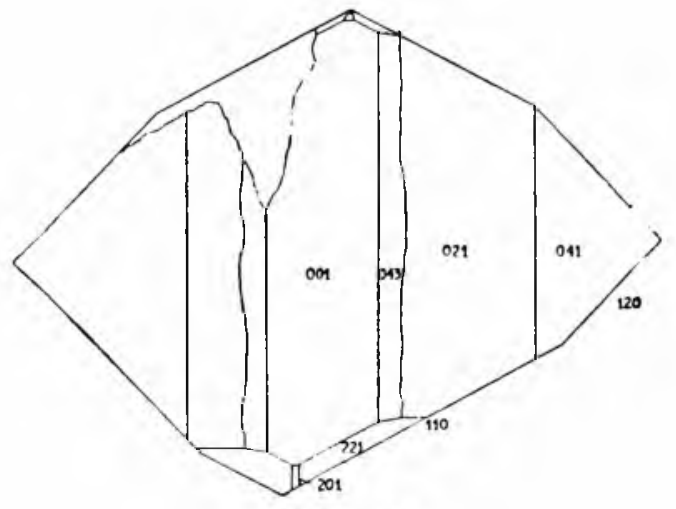

Fig. 3

$\mathrm{O}$ cristal exibe hábito prismático. As formas mais desenvolvidas são as duas únicas da zona [001], $\{110\}$ e $\{120\}$, e na zona [100], as formas $\{021\}$ e $\{041\}$. O pinacoide (001) desenvolve-se regularmente. A face que atinge porém, maior tamanho no cristal, é a de simbolo (110), como se póde observar na fig. 1. Como de regra, os pinacoides $\{100\}$ e $\{010\}$ não se acham presentes no topázio, objéto de nosso estudo. No local correspondente à face (201), que se existisse seria muito reduzida, nota-se um plano abaúlado para o qual não se pode atribuir símbolo algum, como mostra a fig. 3.

Os ângulos diedros foram medidos com auxilio do goniòmetro de aplicação. Verificaram-se, portanto, êrros experimentais mais ou menos da ordem de $1^{\circ}$, aproximação bem razoável para uma simples identificação de faces. 


\section{Summary}

Note about a single topaz from Arassuai, Minas Gerais, Brazil.

This crystal comes from the place named Arassuai, in the State of Minas Gerais, Brazil. The topaz occurs here, in pegmatite dikes wich are enclosed in gneisses. The crystal is colorless, except for a slight blue tint. Dimensions, according to the crystallographic axes, are:

(x) $a_{1}=17,85 \mathrm{~cm}, \quad(y) a_{2}=23,5 \mathrm{~cm}, \quad(z) a_{3}=18,1 \mathrm{~cm}$.

Weight $=12,440 \mathrm{~kg}$.

It is prismatic, $\{110\}$ and $\{120\}$ predominating. Faces in the prismatic zone [001] are vertically striated. $\{043\}$ and $\{041\}$ in the horizontal zone [001] show imperfections in the surfaces due to growth structure. The base (001) shows rhombic and oval figures whose sides are parallel to the edges of the crystal (001)/(110) .

Measurements were not accurate. The interfacial angles were measured by means of the contact on hand-goniometer.

Observed forms :

$\{110\},\{120\},\{001\},\{043\},\{021\},\{041\},\{201\} .\{221\}$.

\section{Bibliografia}

1. Derby, Orville A., - "On the mode of occurrence of topaz near Ouro Preto, Brazil" Am. Jour Sci. 11, 25 - 35 (1901).

2. Doelter, C., - "Handbuch der Mineralchemie" : Verlas von Theodor Steinkopff - Dresden und Leipzig. 2, (1914), 19 .

3. Ferreira, Francisco I., _ "Diccionário Geográfico das Minas do Brasil" : Imprensa Nacional (1885) $624-634$.

4. Guimarães, D. e Souza, H. C. Alves de, - "Estudos sôbre o euclásio de Trino, Hargreaves, municipio de Ouro Preto" : An. da Acad. Brasileira de Ciências, t. 4, 33-34, (1932)

5. Kenngott, A., - "Über Euklas, Topas, Diamant und Pyrrhoțin aus Brasilien": Neues Jarhb. Min., 1, 351 - 358 (1887)

6. Laspeyres, H., - "Der scheibare Hemimorphismus des Topas" : Zeitschr für Krist. und Min., 1, 351-358 (1887)

7 Leonardos, Othon H., - "Tântalo, Nióbio, Urânio e ládio no Brasil" : D. N. P M., 11, 19, Rio de Janeiro (1936).

8. Reis, Esmeraldino, - "Os topázios de Ferros" : Min. e Met. 6, 39-41

- Rio de Janeiro (1941)

9. Silva, J P da, - "Nota sôbre o topázio de Arassuaí, (Minas Gerais) : Mineralogia n. ${ }^{\circ} 3,59-65$, São Paulo (1939)

10. Williams, A. F., - "The genesis of the diamond" : Ernest Renn Limited, London, 2 (1932), $481-515$ 